\title{
Inflation, Information Rigidity, and the Sticky Information Phillips Curve
}

\author{
César Carrera* y Nelson Ramírez-Rondán* \\ * Banco Central de Reserva del Perú.
}

\author{
DT. No 2013-017 \\ Serie de Documentos de Trabajo \\ Working Paper series \\ Diciembre 2013
}

Los puntos de vista expresados en este documento de trabajo corresponden a los autores y no reflejan necesariamente la posición del Banco Central de Reserva del Perú.

The views expressed in this paper are those of the authors and do not reflect necessarily the position of the Central Reserve Bank of Peru. 


\title{
Inflation, Information Rigidity, and the Sticky Information Phillips Curve
}

\author{
César Carrera \\ Central Bank of Peru
}

\author{
Nelson Ramírez-Rondán \\ Central Bank of Peru
}

December 2013

\begin{abstract}
One of the most important structural relationships for policy makers is the Phillips curve; thus, this topic is the focus of ongoing theoretical and empirical research. We estimate the degree of information stickiness implied by the sticky information Phillips curve proposed by Mankiw and Reis (2002). Using threshold models we identify regimes of high and low inflation and find that each regime is associated with a specific degree of information stickiness. We find evidence that agents update information faster when inflation is higher.
\end{abstract}

JEL Classification: C22, C26, E31, E52

Keywords: Inflation, Sticky Information, Phillips Curve, Threshold model

\section{Resumen}

La curva de Phillips es una de las relaciones estructurales más importantes para las autoridades de política. Es por ello que mucha de la investigación teórica y empírica se centra en descubrir sus principales características. En este documento se estima el grado de rigidez de información que se deriva de la curva de Phillips de Mankiw y Reis (2002). El uso de modelos con umbrales nos permite identificar regímenes de alta y baja inflación. Nuestros resultados indican que cada régimen está asociado con un grado de rigidez diferente. Se encuentra evidencia de que los agentes económicos actualizan información más rápido cuando la inflación es más alta.

We would like to thank Carl Walsh, Thomas Wu, Peter Klenow, Uwe Hassler, Yuriy Gorodnichenko, Juan J. Dolado, Federico Ravenna, Todd Walker, and Carlos Carvalho for valuable comments and suggestions. We would also like to thank the seminar participants at the Macro Workshop at UC Santa Cruz and at the Gerzensee Study Center. All remaining errors are ours.

César Carrera is a researcher in the Macroeconomic Modelling Department at the Central Bank of Peru, Jr. Miró Quesada 441, Lima, Peru. Email: cesar.carrera@bcrp.gob.pe

Nelson Ramírez-Rondán is a researcher in the Research Division at the Central Bank of Peru, Jr. Miró Quesada 441, Lima, Peru. Email address: nelson.ramirez@bcrp.gob.pe 


\section{Introduction}

The international policy environment is the subject of continuing research because policy makers require a better description of the underlying determinants of structural relationships than is currently available. This improved description provides better tools for evaluating policy actions and their effects. Therefore, significant time and effort have been recently devoted to reconsidering the explanations contained in the previous literature or to validating previous findings. In this regard, most central banks rely on forecasts of future inflation using a Phillips curve to set their instruments; this is the case, for example, with the Federal Reserve, the Bank of England, and the Bank of Canada.

The central role of the Phillips curve framework has led to research focused on alternative approaches to validating its key parameters. While estimations of the New Keynesian Phillips curve (NKPC) are centered on the frequency with which firms change prices, estimations of the sticky information Phillips curve (SIPC) are focused on the level of firms' inattentiveness.

A relatively new literature has focused on the sticky information argument proposed by Mankiw and Reis (2002) as a way to solve the problems identified with the NKPC by replacing the sticky price assumption. Mankiw and Reis's modeling strategy is based on the argument that information about macroeconomic conditions diffuses slowly through the population. Thus, prices are always changing, but price-setting decisions are not always based on current information. Mankiw and Reis call this situation "sticky information." They assume that, each period, a fraction of firms update their information and compute optimal prices based on that information, while the remaining firms continue to set prices based on old plans and outdated information.

In the context of the Phillips curve, the sticky information model implies that the price level depends on expectations of the current price level formed in the past, as some price setters are still setting prices based on past decisions (because of the cost of either acquiring information or reoptimization).

Even though the recent literature has emphasized the need to model both price stickiness and sticky information, estimating the degree of information rigidity by itself may provide more insight about this important structural parameter. For example, Korenok (2008) cannot formally reject the SIPC; Klenow and Willis (2007) find that price changes in the U.S. CPI micro data reflect information older than that predicted by a flexible information model; and Kiley (2007) finds that the SIPC and the one-lag hybrid NKPC have similar performance. A more stable monetary policy and the context of low inflation around the world are perhaps reasonable arguments to estimate sticky information, keeping in mind its potential role as a complementary form of rigidity to price stickiness.

The gradual diffusion of information across the population assumed by the sticky information model has received some empirical support by using survey data. Carroll (2003) uses a two-agent epidemiology expectation model of information transmission and estimates the rate of diffusion of inflation forecasts from professional forecasters to households and finds the results in line 
with those of Mankiw and Reis (2002). Döpke et al. (2008b) and Carrera (2012) provide similar estimates using Carroll's approach. Döpke et al. (2008b) study the case of European countries, while Carrera (2012) makes a positive case for the diffusion from professional forecasters to firms' general managers and argues that the rigidity of managers' expectations is the key to the SIPC. They all find that the data support the epidemiology expectation model.

This paper provides consistent SIPC estimates for the U.S. and for OECD countries, using the time series approach of Khan and Zhu (2006). We find evidence that rejects the flexible information hypothesis in favor of sticky information. This result is also consistent with that found in Coibion and Gorodnichenko (2012), who use survey data analysis.

We use threshold models to identify high- and low- inflation regimes. By using Khan and Zhu's strategy, we estimate the SIPC for each identified regime. The slope of the SIPC changes between regimes. As a matter of fact, the information updating process seems to be higher when the inflation rate is higher. This evidence suggests that economic agents are more aware of macroeconomic conditions when inflation is higher; that is, missing information during highinflation periods is costly. On the other hand, during low inflation regimes there are few incentives for updating information; that is, stable macroeconomic conditions make the information updating process about macroeconomic conditions slow. Our result is also consistent with that of Mackowiak and Wiederholt (2009); that is, how rational inattention is related to the idea that sticky information should differ based upon the level of inflation.

In line with the discussion of Lucas (1973), Ball, Mankiw, and Romer (1988), and Kiley (2007) regarding the exogeneity of the degree of price stickiness, this paper supports a similar discussion in the context of the degree of information stickiness. We find evidence that suggests a positive relationship between the degree of information stickiness and the level of inflation. Thus, this paper also contributes to the existing literature by providing further evidence of state-contingent and time-dependent inflation processes in the context of the Phillips curve.

The rest of this paper is structured as follows: section 2 contains the baseline model of Mankiw and Reis (2002). In section 3, we estimate the SIPC, following Khan and Zhu's (2006) strategy. In section 4, we present the results of threshold estimations for high- and low- inflation regimes. Section 5 concludes.

\section{Baseline Sticky Information Phillips Curve}

Every firm sets its price every period, but firms gather information and re-compute optimal prices slowly over time. In each period, a fraction $\lambda$ of firms obtain new information about macroeconomic conditions (such as inflation and output) and $(1-\lambda)$ firms continue to set prices based on old plans (outdated information). Firms with updated information compute a new path of optimal prices.

Each firm has the same probability of being one of the firms updating its information set, regardless of how long it has been since its last update. On average, the expected time for a firm to update its prices is $1 / \lambda$. 
A firm's optimal price that maximizes expected profits at any given point in time is $p_{t}^{*}=$ $p_{t}+\alpha y_{t}$, where $p_{t}$ is the overall price level and $y_{t}$ is the output gap (or aggregate demandrelated variable). ${ }^{1}$ The desired price depends on the overall price level and output gap, so a firm's desired relative price rises in booms and falls in recessions. Also notice that a small $\alpha$ means that each firm gives more weight to the changes in prices set by other firms rather than to the level of aggregate demand.

A firm that last updated its plans $j$ periods ago sets its price as the expected value of the optimal price $j$ periods ago: $x_{t}^{j}=E_{t-j} p_{t}^{*}$.

The aggregate price level is the average of the prices of all firms in the economy, assuming that the arrival of decision dates is a Poisson process given by: $p_{t}=\lambda \sum_{j=0}^{\infty}(1-\lambda)^{j} x_{t}^{j}$.

The price level is then defined by $p_{t}=\lambda \sum_{j=0}^{\infty}(1-\lambda)^{j} E_{t-j}\left(p_{t}+\alpha y_{t}\right)$ so that the baseline SIPC is defined as:

$$
\pi_{t}=\frac{\lambda \alpha}{1-\lambda} y_{t}+\lambda \sum_{j=0}^{\infty}(1-\lambda)^{j} E_{t-1-j}\left(\pi_{t}+\alpha \Delta y_{t}\right),
$$

where $\Delta y_{t}=y_{t}-y_{t-1}$ defines the growth rate of output and $\pi_{t}=p_{t}-p_{t-1}$ defines the growth rate of prices (inflation).

In this set-up, inflation depends on output, past expectations of current inflation, and past expectations of changes in current output growth.

\section{Estimation Methodology}

The usual procedure used to estimate a SIPC is nonlinear Ordinary Least Squares (OLS) (Khan and Zhu, 2006; Döpke et al., 2008a; and Coibion, 2010). Khan and Zhu's (2006) method uses publicly available data for estimating expectations. Döpke et al. (2008a) and Coibion (2010) use information from survey data and plug the responses into forecasts of inflation and economic growth. The use of survey data limits the truncation value of the Phillips curve. Döpke et al. (2008a) consider only two levels of truncation (at four and six periods). Coibion (2010) additionally uses the forecasts from estimated VARs to expand the level of truncation to 12 periods.

In this section we follow Khan and Zhu's strategy and estimate the SIPC by nonlinear OLS for 1971-2007 using quarterly data for the U.S. We first estimate the SIPC considering the joint estimation of information and real rigidities. Then, we estimate the information rigidity value holding constant the real rigidity level; that is, we impose a level of real rigidity with a value that is consistent with the literature. We show that real rigidities values around 0.1 are reasonable.

\footnotetext{
${ }^{1}$ For a similar relationship of optimal price setting in the context of rational inattention, see Reis (2006).
} 


\subsection{Khan and Zhu's Estimation Strategy}

Khan and Zhu's (2006) strategy consists of the truncation of Equation (1). The empirical counterpart of the SIPC suggested by Khan and Zhu (2006) is:

$$
\pi_{t}=\frac{\lambda \alpha}{1-\lambda} y_{t}+\lambda \sum_{j=0}^{j^{\max }}(1-\lambda)^{j} E_{t-1-j}\left[\pi_{t}+\alpha \Delta y_{t}\right]+u_{t}
$$

where $u_{t}=\lambda \sum_{j=j^{\max }+1}^{\infty}(1-\lambda)^{j} E_{t-1-j}\left[\pi_{t}+\alpha \Delta y_{t}\right]$.

For a given $\lambda$, the approximation error, $u_{t}$, gets theoretically smaller with an increase in the truncation level $\left(j^{\max }\right)$. Khan and Zhu (2006) examine the sensitivity of their estimates to the choice of the truncation point. Based on their methodology and the sample period, the longest truncation level suggested is 20 quarters (i.e. $j^{\max }+1=20$ ).

To estimate equation (2), Khan and Zhu (2006) need a total of $\left(j^{\max }+1\right)$ past expectations (or forecasts) of current variables $\pi_{t}$ and $\Delta y_{t}$ for each $t$. Each of these forecasts is based on past information from periods $t-1, t-2, \cdots, t-1-j^{\text {max }}$, respectively.

Khan and Zhu (2006) consider two methods for measuring the output gap: the HodrickPrescott output gap and the quadratic detrended output gap. They also consider three measurements of inflation: the consumer price index (CPI), core inflation, and the GDP deflator.

Khan and Zhu (2006) do not discuss the problems of single-equation methods in estimating the Phillips curve. This type of estimation is subject to the endogeneity problem between the output gap and inflation (single-equation bias). A second problem is the time period selected for their estimation. Khan and Zhu's study (2006) covers a period of relatively lower inflation than the 1970s, and the data from the 1970s are used only to estimate past expectations. We take into account those critiques: The sample period for the SIPC for the U.S. goes from 1971 to 2007, and we use the lag of the output gap as an instrument for the output gap. ${ }^{2}$

To obtain the forecasts required for inflation and the output gap, Khan and Zhu (2006) consider two methods for generating out-of-sample forecasts: (i) univariate autoregressive models, and (ii) bivariate VARs. ${ }^{3}$

Rather than using the forecasting power in the time series approach for estimating the expectations of inflation and output, we use the log likelihood function of the time series specification. We use the Schwarz information criterion for the optimal length of the ARIMA model. This method contrasts with that of Khan and Zhu (2006), who choose the optimal number of lags based on the smallest root-of-mean-squared forecasting errors in the ARIMA. A similar argument applies to the VAR estimations.

Following Khan and Zhu (2006), we also eliminate the largest and the smallest forecast when taking the average in order to reduce the sensitivity to large outliers and use the forecast of the

\footnotetext{
${ }^{2}$ Coibion (2010) proposes instrumental variables non-linear least squares as well as valid instruments.

${ }^{3}$ Khan and Zhu (2006) estimate bivariate VARs using six forecasting variables and then take a simple average of the forecasts from each VAR. One advantage of this procedure is that it reduces the sensitivity of forecasts to different time periods and potential changes in the informational content of the variables.
} 
output gap growth as the output gap forecast. ${ }^{4}$

Similar to Khan and Zhu (2006), we test the null hypothesis $H_{0}: \lambda=1$ (no information stickiness) against the alternative, $H_{1}: \lambda<1$ (some information stickiness).

\subsection{Joint Estimation of Information and Real Rigidities}

Khan and Zhu (2006) estimate the degree of information stickiness (parameter $\lambda$ ), conditional on an imposed degree of real rigidity (parameter $\alpha$ ). In this section, we intend to provide a robust link between nominal and real activities. The degree of information stickiness (parameter $\lambda$ ) and the degree of real rigidity (parameter $\alpha$ ) can be jointly estimated by using non-linear least squares. In other words, we can minimize the following objective function for different values of those parameters:

$$
(\widehat{\lambda}, \widehat{\alpha})=\underset{(\widehat{\lambda}, \widehat{\alpha})}{\operatorname{argmax}}\left[\pi_{t}-\frac{\lambda \alpha}{1-\lambda} \widehat{y}_{t}-\lambda \sum_{j=0}^{j^{\max }}(1-\lambda)^{j} E_{t-1-j}\left[\pi_{t}-\alpha \Delta y_{t}\right]\right]^{2},
$$

where $\widehat{y}_{t}$ are predicted values (uncorrelated with the error term) and $y_{t}$ is the output gap (the lag of output gap $y_{t-1}$ is used as instrument).

Figure 1(a) shows the objective function on the $\alpha$ parameter space for the core inflation and the Hodrick-Prescott output gap and considers $j^{\max }=19$ quarters. The $\alpha$ that minimizes the objective function is 0.01 , which is consistent with 0.87 of information rigidity. In Table 1 , we report $\alpha$ values between 0.01 and 0.03 when other measures of inflation and the output gap are used. Point estimates indicate that information rigidity ranges between 1.2 and 1.4 quarters.

Figure 1: Information and real rigidity

(a) Objective function for different real rigidity values

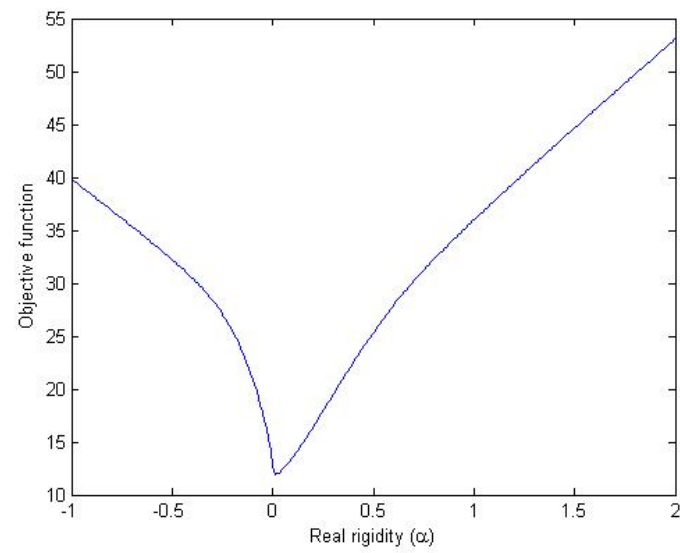

(b) Information rigidity versus real rigidity

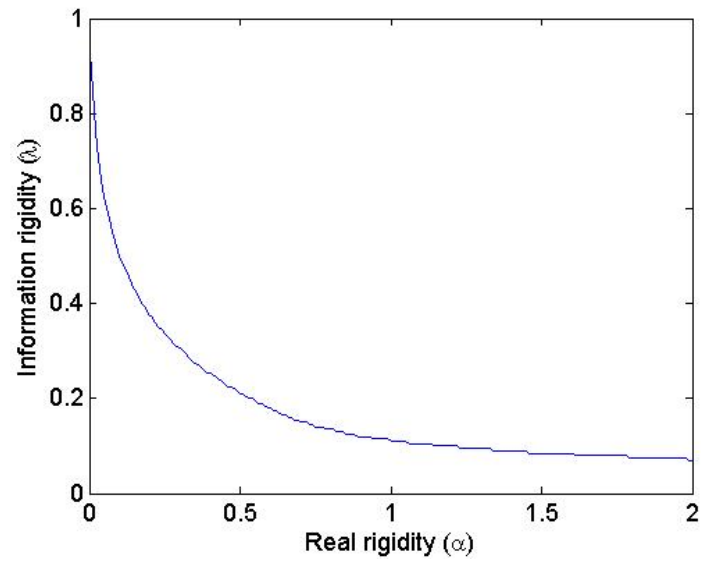

The relationship between information and real rigidities seems to be monotonic. Figure 1(b) clearly illustrates this point. As Coibion (2010) argues, a $\lambda$ close to one minimizes both the real-

\footnotetext{
${ }^{4}$ For more details, see Stock and Watson (2001).
} 
time forecast error and the inertia effects. Coibion (2010) states that there is no information rigidity at all. On the other hand, the data imply a small and positive link between inflation and the output gap. From Equation (2), an estimator of $\lambda$ close to one implies a small $\alpha$. The combined effect from these two parameters implies a small effect of output gap over inflation.

Table 1: Estimation of information and real rigidities

\begin{tabular}{|c|c|c|c|c|c|}
\hline & & $\overline{y^{\text {Quadra }}}$ & Detrended & $y^{\text {Hodrick }}$ & \\
\hline & $j^{\max }+1$ & $\widehat{\alpha}$ & $\widehat{\lambda}$ & $\widehat{\alpha}$ & $\widehat{\lambda}$ \\
\hline$\pi^{C P I \text { inflation }}$ & 5 Quarters & 0.02 & 0.75 & 0.01 & 0.86 \\
\hline & & $(0.015)$ & $(0.110)$ & $(0.013)$ & $(0.121)$ \\
\hline & 8 Quarters & 0.02 & 0.75 & 0.01 & 0.86 \\
\hline & & $(0.015)$ & $(0.111)$ & $(0.013)$ & $(0.121)$ \\
\hline & 12 Quarters & 0.02 & 0.75 & 0.01 & 0.86 \\
\hline & & $(0.015)$ & $(0.111)$ & $(0.013)$ & $(0.121)$ \\
\hline & 20 Quarters & 0.02 & 0.75 & 0.01 & 0.86 \\
\hline & & $(0.015)$ & $(0.011)$ & $(0.013)$ & $(0.121)$ \\
\hline$\pi^{\text {Core inflation }}$ & 5 Quarters & 0.03 & 0.67 & 0.02 & 0.78 \\
\hline & & $(0.018)$ & $(0.111)$ & $(0.011)$ & $(0.141)$ \\
\hline & 8 Quarters & 0.02 & 0.74 & 0.01 & 0.87 \\
\hline & & $(0.016)$ & $(0.129)$ & $(0.015)$ & $(0.154)$ \\
\hline & 12 Quarters & 0.02 & 0.74 & 0.01 & 0.87 \\
\hline & & $(0.016)$ & $(0.129)$ & $(0.015)$ & $(0.154)$ \\
\hline & 20 Quarters & 0.02 & 0.74 & 0.01 & 0.87 \\
\hline & & $(0.016)$ & $(0.129)$ & $(0.015)$ & $(0.154)$ \\
\hline$\pi^{G D P}$ deflator & 5 Quarters & 0.02 & 0.72 & 0.01 & 0.85 \\
\hline & & $(0.011)$ & $(0.093)$ & $(0.010)$ & $(0.109)$ \\
\hline & 8 Quarters & 0.02 & 0.72 & 0.01 & 0.85 \\
\hline & & $(0.011)$ & $(0.094)$ & $(0.010)$ & $(0.109)$ \\
\hline & 12 Quarters & 0.02 & 0.72 & 0.01 & 0.85 \\
\hline & & $(0.011)$ & $(0.094)$ & $(0.010)$ & $(0.109)$ \\
\hline & 20 Quarters & 0.02 & 0.72 & 0.01 & 0.85 \\
\hline & & $(0.011)$ & $(0.094)$ & $(0.010)$ & $(0.109)$ \\
\hline Average & & 0.02 & 0.73 & 0.01 & 0.85 \\
\hline & & $(0.014)$ & $(0.106)$ & $(0.012)$ & $(0.128)$ \\
\hline In quarters & & & 1.4 & & 1.2 \\
\hline
\end{tabular}

Note: The sample period is 1971Q1-2007Q4. Standard errors are in parentheses.

\subsection{Information Rigidity with an Imposed Real Rigidity Value}

We turn to the estimation of the degree of information stickiness subject to an imposed degree of real rigidity $(\alpha)$. In regard to Reis (2006), $\alpha$ has two important implications. First, a small $\alpha$ would lead to both long periods of inattentiveness and a small $\lambda$ (in the context of the "inattentive producer"). Moreover, a smaller $\alpha$ generates larger real effects of nominal shocks if $\lambda$ is fixed. 
Reis (2006) points out that the smaller $\alpha$ is, the stronger are strategic complementarities in pricing, implying that firms that are adjusting prices wish to set their individual prices close to those set by non-adjusting firms. Through these two roles, a small $\alpha$ leads to a limited adjustment of prices and thus large real effects of nominal shocks.

Most of the literature agree on a value around 0.1 for $\alpha$. Taking into account both micro and aggregate evidence, Woodford (2003) concludes that a value for $\alpha$ between 0.10 and 0.15 is adequate. Reis (2006) cites Chari, Kehoe, and McGrattan (2000) and sets $\alpha=0.17$; Rotemberg and Woodford (1997) set $\alpha=0.13$; and Ball and Romer (1990) set the parameter $\alpha=0.13$ as reasonable values. ${ }^{5}$

Some other values used in the literature for estimating the SIPC for the U.S. are Khan and Zhu (2006), $\alpha$ equal to 0.10; Reis (2006), $\alpha$ equal to 0.11; and Coibion (2010), $\alpha$ equal to 0.20. Regarding cross-country analysis for four European countries, Döpke et al. (2008a) use both values of $\alpha, 0.10$ and 0.20 , as a way to test for robustness.

In this section, we estimate $\lambda$ subject to $\alpha$ equal to 0.10 . Table 2 shows that $\lambda$ is between 0.45 and 0.52 , which implies a degree of information rigidity around two quarters (i.e., we reject the null of flexible information in all cases). These results are consistent for different levels of truncation $\left(j^{\max }\right)$ and measures of inflation and output gap.

\subsection{Evidence from OECD Countries}

We replicate the analysis for 12 OECD countries, imposing a degree of real rigidity and taking into consideration the availability of data. We reject the null hypothesis of flexible information in all cases. It seems fair to say that sticky information theory implies that countries with higher inflation levels or higher inflation volatility experience lower levels of inattentiveness. A simple cross-country analysis support this hypothesis. ${ }^{6}$

In Figure 2, we plot $\lambda$ and average inflation for each country. This figure suggests that in countries with higher inflation, it is expected that price setters update information more frequently. In line with Reis (2006), it is more costly for firms in countries with lower inflation to update information because updating requires acquiring, processing, and absorbing information so that they remain inattentive. Reis (2006) suggests that it is easier to plan ahead in a context of lower uncertainty, which reduces the incentives to update information on macroeconomic conditions.

Even though it is possible to argue that high inflation should not be costly if inflation is "chronic," 7 we also consider the volatility of inflation. The positive relationship between $\lambda$ and this measurement of uncertainty still holds (see Figure 3), which suggests an additional factor that affects $\lambda$.

\footnotetext{
${ }^{5}$ See also Gali and Gertler (1999) for a discussion of $\alpha$ in the context of the NKPC.

${ }^{6}$ See the Appendix for details of the sample and data involved.

${ }^{7}$ If the inflation rate is high every year, agents expect a high inflation every year, therefore, their level of inattentiveness remains the same every year as well.
} 
Table 2: Estimation of information rigidity $(\alpha=0.1)$

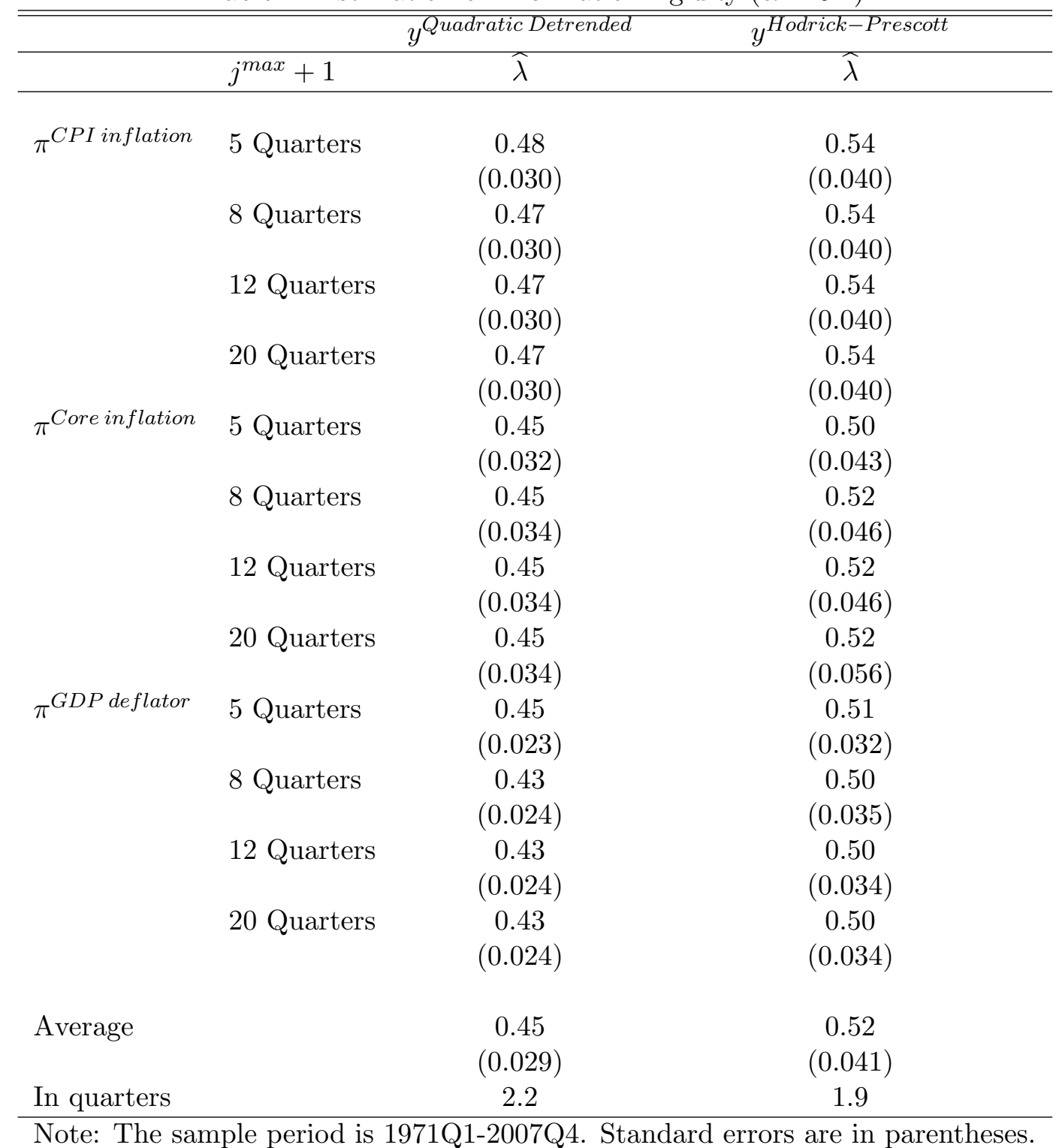


Figure 2: Information rigidity and inflation for OECD countries

(a) CPI inflation and detrended output gap

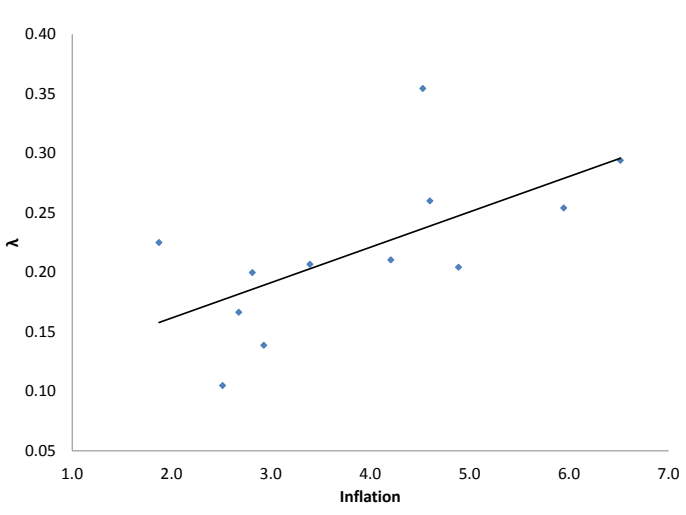

(b) CPI inflation and Hodrick-Prescott output gap

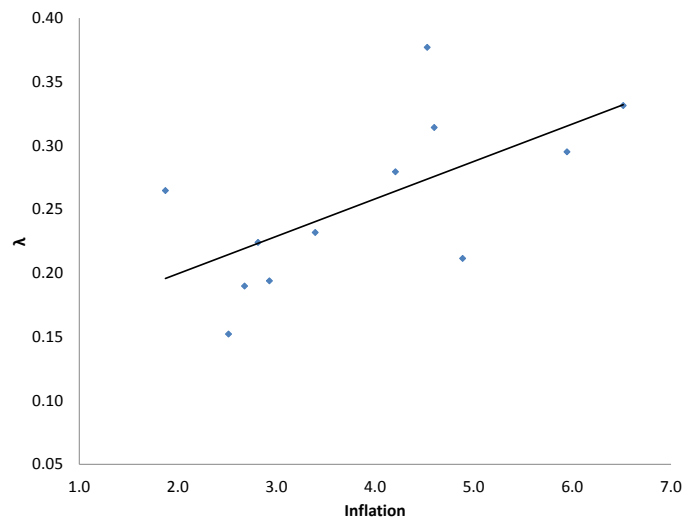

Note: The information rigidity estimate for each country is the average for different truncation levels.

Figure 3: Information rigidity and inflation volatility for OECD countries

(a) CPI inflation and detrended output gap

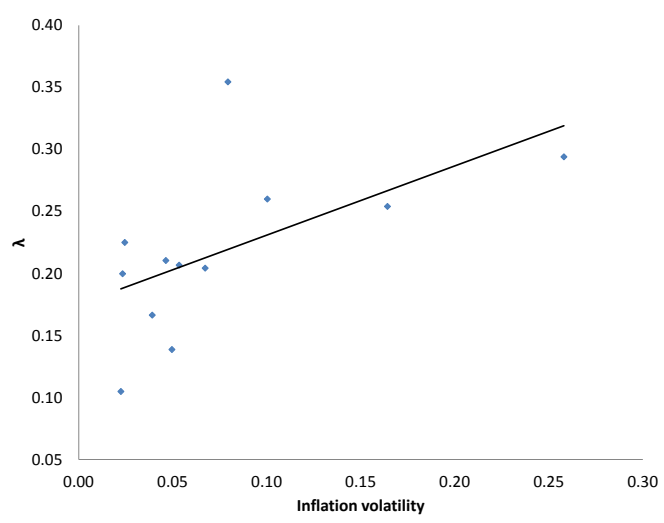

(b) CPI inflation and Hodrick-Prescott output gap

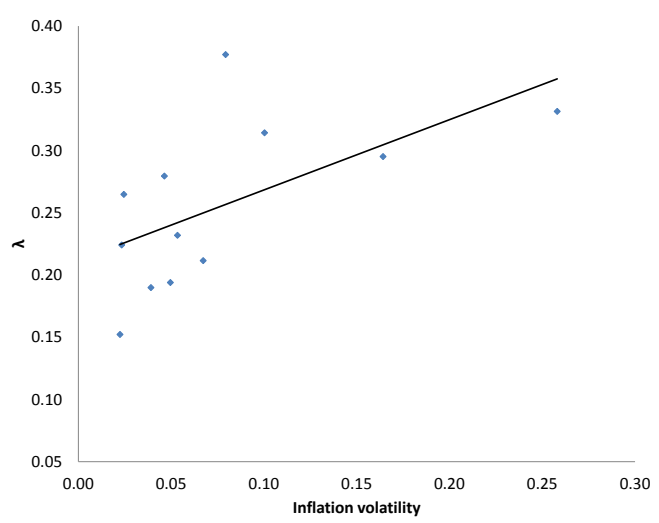

Note: The information rigidity estimate for each country is the average for different truncation levels. 


\section{Threshold Modeling Strategy}

As suggested in the previous section, there is evidence that points to a change in the slope of the SIPC. This change may have implications for the design of optimal monetary policy. Walsh (2010) presents an exercise on the difference in the dynamics of inflation and the output gap for different degrees of information stickiness for the U.S. in response to a monetary policy shock. Following Mankiw and Reis (2002), Walsh (2010) shows that the maximum effect and the persistence of the shock change when the slope of the SIPC is modified.

Figure 4 shows the U.S. CPI inflation, core inflation, and the GDP deflator inflation. All the measures suggest that it is possible to contrast periods of high inflation (from the 1970s to the early 1980s) with periods of low inflation (from the mid- 1980s to 2007), which suggests a change in the regime (state) of the inflation patterns, as pointed out in Kiley (2007).

Figure 4: U.S. inflation

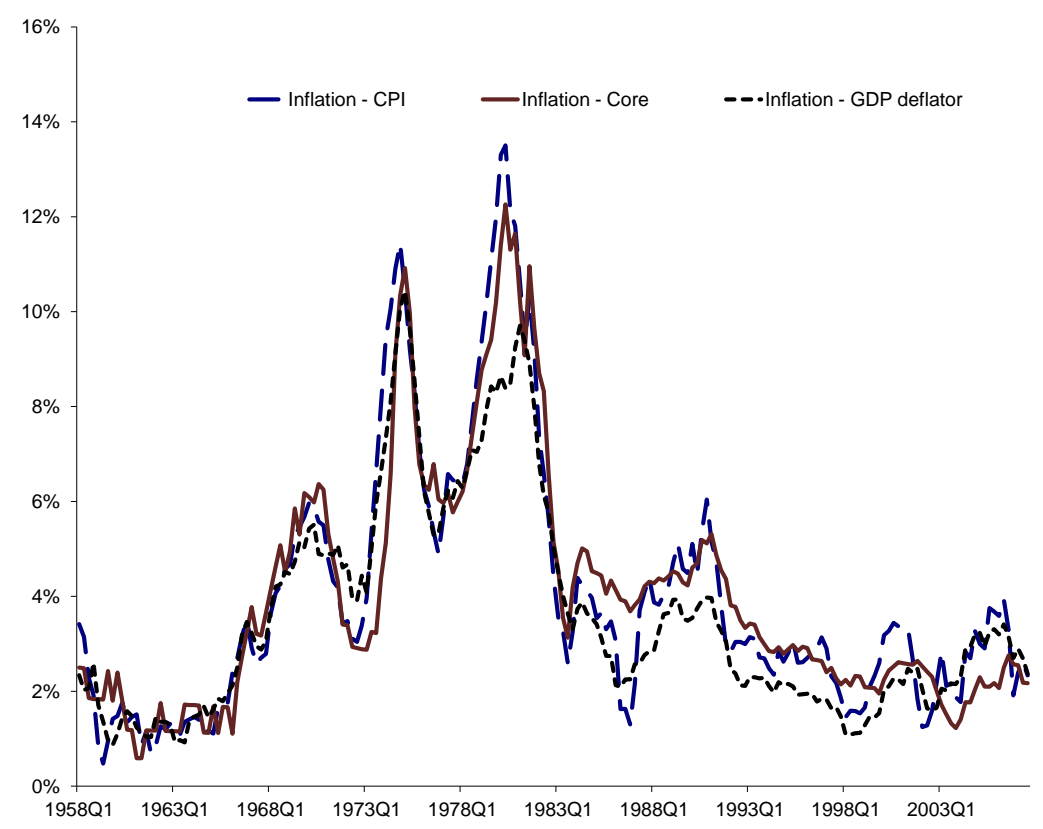

In the remainder of this section we add more rigorous methodology and estimate both time and inflation threshold models. We evaluate whether two regimes are present in the U.S. data and whether this change in regime has any effect on the slope of the SIPC, as suggested in our previous section.

\subsection{Time and Inflation Threshold Models}

Here we set the threshold models to be estimated. We first set a threshold model in which time is the threshold variable: 


$$
\pi_{t}= \begin{cases}\frac{\lambda_{1} \alpha}{1-\lambda_{1}} y_{t}+\lambda_{1} \sum_{j=0}^{j^{\max }}\left(1-\lambda_{1}\right)^{j} E_{t-1-j}\left[\pi_{t}+\alpha \Delta y_{t}\right]+u_{t} \quad \text { if } \quad t \geq \tau \\ \frac{\lambda_{2} \alpha}{1-\lambda_{2}} y_{t}+\lambda_{2} \sum_{j=0}^{j^{\max }}\left(1-\lambda_{2}\right)^{j} E_{t-1-j}\left[\pi_{t}+\alpha \Delta y_{t}\right]+u_{t} \quad \text { if } \quad t<\tau,\end{cases}
$$

where $\lambda_{1}$ and $\lambda_{2}$ are information rigidity parameters for low- and high- inflation periods, respectively, and $\tau$ is the threshold parameter. ${ }^{8}$

We considers two estimations of model (4) in which we (i) impose a $\tau=1982 \mathrm{Q} 4$; that is, we split the sample in two: from 1971 to 1982 (period of high inflation, with an average of 7.6 percent) and from 1983 to 2007 (period of low inflation, with an average of 3.1 percent), ${ }^{9}$ and (ii) internally allow the threshold parameter $\tau$ in the model to be estimated.

We propose a second model in which high inflation is determined for inflation rates higher than a threshold value. A natural candidate for the threshold variable is the current level of inflation, but by construction this variable is endogenous to the model. A basic assumption in threshold models is that the threshold variable has to be exogenous, then we consider the lag of inflation as a threshold variable. We set the following model

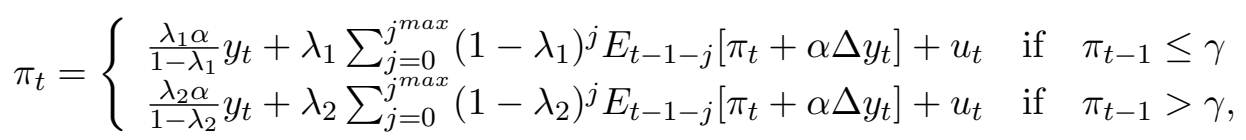

where $\lambda_{1}$ and $\lambda_{2}$ are information rigidity parameters when the inflation is low and high, respectively, and $\gamma$ is the threshold parameter. ${ }^{10}$

\subsection{Results}

Table 3 presents the regressions for Equation (4) in which a cutting point between high and low inflation is imposed in 1982Q4. We reject the null of flexible information in all cases. For the period 1971-1982, the degree of information stickiness $\left(\widehat{\lambda}_{2}\right)$ is 0.52 and 0.54 using a quadratic detrended and the Hodrick-Prescott output gap, respectively. This result suggests that price setters update information more frequently (two quarters on average) when inflation is higher. In contrast, the degree of information stickiness $\left(\widehat{\lambda}_{1}\right)$ is around 0.34 in the second period, which implies an average duration of information stickiness of three quarters when low inflation is considered. These results seems to be robust to different measures of inflation and the output gap.

We estimate Equation (4) with an internal estimate of the time change-point that defines either high or low inflation. In Table 4 , we report the estimated $\tau(\widehat{\tau})$ for the change from high to low inflation and its asymptotic 90 percent confidence interval. The estimate of the threshold level is around 1981, except for the case of the GDP deflator and the Hodrick-Prescott output gap (the time threshold is 1975Q3). We infer two classes of regimes separated by the point

\footnotetext{
${ }^{8}$ Here, the date that separates the sample in low and high inflation is identified.

${ }^{9} \mathrm{We}$ also notice that the variance of the inflation rates decreases and goes from 0.09 in the first period to 0.01 in the second period.

${ }^{10}$ For a theory of least squares estimation and inference on models similar to equations (4) and (5), see Chan (1993) and Hansen (2000).
} 
Table 3: Information rigidity in high and low inflation $\left(\alpha=0.1\right.$ and $j^{\text {max }}+1=5$ quarters $)$

\begin{tabular}{|c|c|c|c|c|}
\hline & \multicolumn{2}{|c|}{$y^{y^{\text {Quadratic Detrended }}}$} & \multicolumn{2}{|c|}{$y^{\text {Hodrick-Prescott }}$} \\
\hline & Low Inflation & High Inflation & Low Inflation & High Inflation \\
\hline \multirow[t]{4}{*}{$\pi^{C P I \text { inflation }}$} & $(t \geq 1982 Q 4)$ & $(t<1982 Q 4)$ & $(t \geq 1982 Q 4)$ & $(t<1982 Q 4)$ \\
\hline & $\widehat{\lambda}_{1}$ & $\widehat{\lambda}_{2}$ & $\widehat{\lambda}_{1}$ & $\widehat{\lambda}_{2}$ \\
\hline & 0.37 & 0.58 & 0.36 & 0.56 \\
\hline & $(0.058)$ & $(0.032)$ & $(0.059)$ & $(0.042)$ \\
\hline \multirow[t]{4}{*}{$\pi^{\text {Core inflation }}$} & $(t \geq 1982 Q 4)$ & $(t<1982 Q 4)$ & $(t \geq 1982 Q 4)$ & $(t<1982 Q 4)$ \\
\hline & $\widehat{\lambda}_{1}$ & $\widehat{\lambda}_{2}$ & $\widehat{\lambda}_{1}$ & $\widehat{\lambda}_{2}$ \\
\hline & 0.30 & 0.49 & 0.27 & 0.53 \\
\hline & $(0.041)$ & $(0.033)$ & $(0.031)$ & $(0.042)$ \\
\hline \multirow[t]{4}{*}{$\pi^{G D P \text { deflator }}$} & $(t \geq 1982 Q 4)$ & $(t<1982 Q 4)$ & $(t \geq 1982 Q 4)$ & $(t<1982 Q 4)$ \\
\hline & $\widehat{\lambda}_{1}$ & $\widehat{\lambda}_{2}$ & $\widehat{\lambda}_{1}$ & $\widehat{\lambda}_{2}$ \\
\hline & 0.37 & 0.49 & 0.37 & 0.53 \\
\hline & $(0.044)$ & $(0.024)$ & $(0.051)$ & $(0.033)$ \\
\hline \multirow[t]{2}{*}{ Average } & 0.35 & 0.52 & 0.33 & 0.54 \\
\hline & $(0.048)$ & $(0.030)$ & $(0.048)$ & $(0.039)$ \\
\hline In quarters & 2.9 & 1.9 & 3.0 & 1.9 \\
\hline
\end{tabular}

Note: The sample period is 1971Q1-2007Q4. Standard errors are in parentheses.

estimate: (i) "high inflation" for periods before $\widehat{\tau}$, and (ii) "low inflation" for further values. The asymptotic confidence intervals for the time threshold values are small, which suggest a lower level of uncertainty about the division of the data.

Table 4: 90\% Asymptotic confidence interval of time threshold estimate

\begin{tabular}{lcccc}
\hline \hline & \multicolumn{2}{c}{$y^{\text {Quadratic Detrended }}$} & \multicolumn{2}{c}{$y^{\text {Hodrick-Prescott }}$} \\
\hline & $\begin{array}{c}\text { Threshold } \\
\text { estimate }(\widehat{\tau})\end{array}$ & $\begin{array}{c}\text { Confidence } \\
\text { interval }\end{array}$ & $\begin{array}{c}\text { Threshold } \\
\text { estimate }(\widehat{\tau})\end{array}$ & $\begin{array}{c}\text { Confidence } \\
\text { interval }\end{array}$ \\
\hline$\pi^{\text {CPI inflation }}$ & $1981 \mathrm{Q} 4$ & {$[1979 \mathrm{Q} 4 ; 1983 \mathrm{Q} 2]$} & $1980 \mathrm{Q} 3$ & {$[1974 \mathrm{Q} 2 ; 1983 \mathrm{Q} 3]$} \\
$\pi^{\text {Core } \text { inflation }}$ & $1981 \mathrm{Q} 4$ & {$[1973 \mathrm{Q} 3 ; 1986 \mathrm{Q} 1]$} & $1981 \mathrm{Q} 4$ & {$[1980 \mathrm{Q} 3 ; 1984 \mathrm{Q} 3]$} \\
$\pi^{\text {GDP deflator }}$ & 1981Q2 & {$[1975 \mathrm{Q} 1 ; 1983 \mathrm{Q} 2]$} & $1975 \mathrm{Q} 3$ & {$[1975 \mathrm{Q} 1 ; 1981 \mathrm{Q} 2]$} \\
\hline
\end{tabular}

Note: Asymptotic critical values are reported in Hansen (2000).

The concentrated likelihood ratio function $L R(\tau)$ for most cases are similar which is suggested from Table 4. We plot the CPI inflation and the detrended output gap case and find that $L R(\tau)=0$ occurs at $\widehat{\tau}=1981 \mathrm{Q} 4$ (see Figure 5a). For the GDP deflator and the Hodrick Prescott case, the likelihood ratio points to 1975Q3; however, a second threshold appears also in 1981Q2, a date that is consistent with all the remaining cases (see Figure 5b). ${ }^{11}$

In Table 5, we show those degrees of information stickiness $\left(\lambda_{1}\right.$ and $\left.\lambda_{2}\right)$ for the implied high-

\footnotetext{
${ }^{11}$ The confidence level are the values of $\tau$ for which $L R(\tau)$ is smaller than the critical value. The threshold value can be identified by plotting $L R(\tau)$ against $\tau$ and drawing a flat line at the critical value level.
} 
Figure 5: Likelihood ratio for threshold models with time as a threshold variable
(a) CPI inflation and
(b) GDP deflator inflation and

quadratic detrended output gap

Hodrick-Prescott output gap
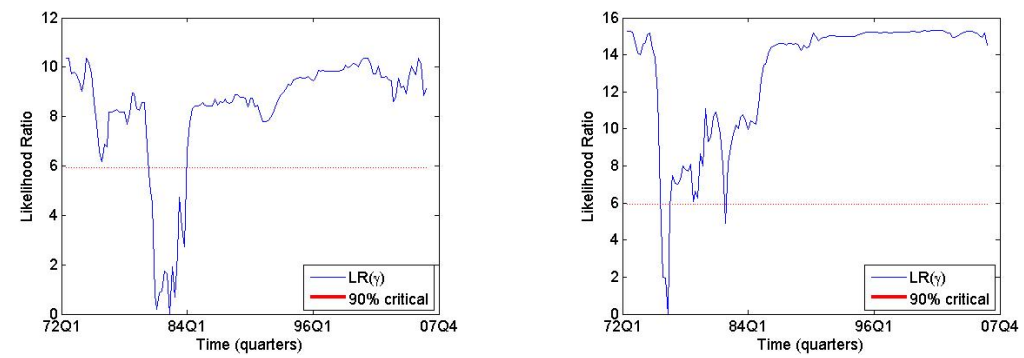

and low- inflation periods. We reject the flexible information hypothesis in all cases. For high inflation $\widehat{\lambda}_{2}$ equals 0.52 and 0.60 using a quadratic detrended and Hodrick-Prescott output gap, respectively. This result suggests that price setters update information about every two quarters on average when inflation is higher. On the other hand, $\widehat{\lambda}_{1}$ equals 0.33 and 0.35 in low inflation periods. This result implies an average duration of information stickiness of three quarters. In general, Tables 3 and 5 are consistent with the hypothesis that at higher levels of inflation, agents update information faster.

Table 5: Information rigidity in high and low inflation $\left(\alpha=0.1\right.$ and $j^{\max }+1=5$ quarters $)$

\begin{tabular}{|c|c|c|c|c|}
\hline & \multicolumn{2}{|c|}{$y^{y^{\text {Quadratic Detrended }}}$} & \multicolumn{2}{|c|}{$y^{\text {Hodrick-Prescott }}$} \\
\hline & Low Inflation & "High Inflation & "Low Inflation & " High Inflation \\
\hline \multirow[t]{4}{*}{$\pi^{C P I \text { inflation }}$} & $(t \geq 1981 Q 4)$ & $(t<1981 Q 4)$ & $(t \geq 1980 Q 3)$ & $(t<1980 Q 3)$ \\
\hline & $\widehat{\lambda}_{1}$ & $\widehat{\lambda}_{2}$ & $\widehat{\lambda}_{1}$ & $\widehat{\lambda}_{2}$ \\
\hline & 0.33 & 0.54 & 0.34 & 0.59 \\
\hline & $(0.049)$ & $(0.033)$ & $(0.042)$ & $(0.042)$ \\
\hline \multirow[t]{4}{*}{$\pi^{\text {Core inflation }}$} & $(t \geq 1981 Q 4)$ & $(t<1981 Q 4)$ & $(t \geq 1981 Q 4)$ & $(t<1981 Q 4)$ \\
\hline & $\widehat{\lambda}_{1}$ & $\widehat{\lambda}_{2}$ & $\widehat{\lambda}_{1}$ & $\widehat{\lambda}_{2}$ \\
\hline & 0.29 & 0.51 & 0.27 & 0.55 \\
\hline & $(0.036)$ & $(0.034)$ & $(0.028)$ & $(0.043)$ \\
\hline \multirow[t]{4}{*}{$\pi^{G D P \text { deflator }}$} & $(t \geq 1981 Q 2)$ & $(t<1981 Q 2)$ & $(t \geq 1975 Q 3)$ & $(t<1975 Q 3)$ \\
\hline & $\widehat{\lambda}_{1}$ & $\widehat{\lambda}_{2}$ & $\widehat{\lambda}_{1}$ & $\widehat{\lambda}_{2}$ \\
\hline & 0.36 & 0.50 & 0.44 & 0.66 \\
\hline & $(0.039)$ & $(0.024)$ & $(0.035)$ & $(0.039)$ \\
\hline \multirow[t]{2}{*}{ Average } & 0.33 & 0.52 & 0.35 & 0.60 \\
\hline & $(0.042)$ & $(0.031)$ & $(0.035)$ & $(0.041)$ \\
\hline In quarters & 3.1 & 1.9 & 2.9 & 1.7 \\
\hline
\end{tabular}

Note: The sample period is 1971Q1-2007Q4. Standard errors are in parentheses.

Finally, we estimate a threshold model for inflation as the threshold variable, i.e., Equation (5). As mentioned before, most threshold estimates are alike. Here we show the estimate for 
the case of the CPI inflation and the quadratic detrended output gap: $L R(\gamma)$ equals zero occurs at $\widehat{\gamma}=1.7$ percent (see Figure $6 \mathrm{a}$ ). We also present the threshold for the core inflation and the Hodrick-Prescott output gap: 2.2 percent (see Figure 6b).

Figure 6: Likelihood ratio for threshold models with inflation as a threshold variable
(a) CPI inflation and
(b) Core inflation and

quadratic detrended output gap

Hodrick-Prescott output gap
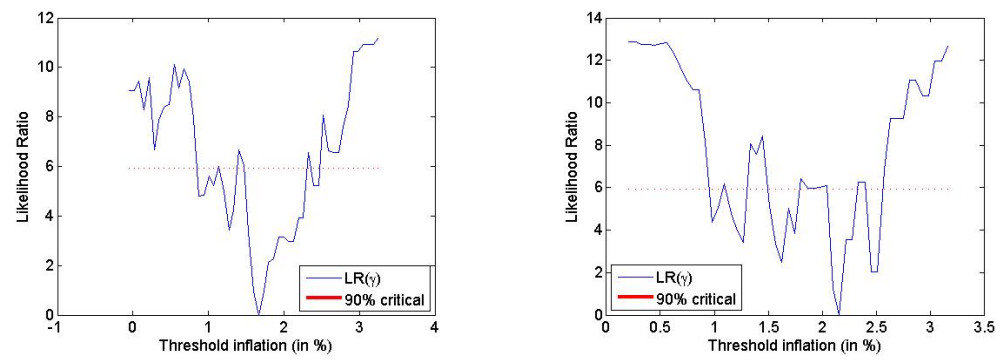

Table 6 reports the point estimate for $\widehat{\gamma}$ and its asymptotic 90 percent confidence interval. The data suggest that there is a change in regime when inflation is higher (or lower) than 1.7 percent. Using different measures of inflation and the output gap, the inflation threshold tend to be at some point between 1.7 and 2.5 percent. We can identify two classes of regimes by the point estimates: (i) "high inflation" for inflation rates higher than $\widehat{\gamma}$, and (ii) "low inflation" for inflation rates lower than $\widehat{\gamma}$.

The asymptotic confidence interval for the threshold level of inflation is small when we consider the detrended quadratic output gap for all measures of inflation, which suggest more accurate results than those of the Hodrick-Prescott output gap.

Table 6: 90\% Asymptotic confidence interval of inflation threshold estimate

\begin{tabular}{lcccc}
\hline \hline & \multicolumn{2}{c}{$y^{\text {Quadratic Detrended }}$} & \multicolumn{2}{c}{$y^{\text {Hodrick-Prescott }}$} \\
\hline & $\begin{array}{c}\text { Threshold } \\
\text { estimate }(\widehat{\gamma})\end{array}$ & $\begin{array}{c}\text { Confidence } \\
\text { interval }\end{array}$ & $\begin{array}{c}\text { Threshold } \\
\text { estimate }(\widehat{\gamma})\end{array}$ & $\begin{array}{c}\text { Confidence } \\
\text { interval }\end{array}$ \\
\hline \multirow{2}{*}{$\pi^{\text {CPI inflation }}$} & $1.67 \%$ & {$[0.88 \% ; 2.46 \%]$} & $1.67 \%$ & {$[-0.05 \% ; 2.85 \%]$} \\
$\pi^{\text {Core inflation }}$ & $2.46 \%$ & {$[2.46 \% ; 2.52 \%]$} & $2.16 \%$ & {$[0.98 \% ; 2.52 \%]$} \\
$\pi^{\text {GDP deflator }}$ & $2.29 \%$ & {$[1.58 \% ; 2.33 \%]$} & $2.29 \%$ & {$[0.29 \% ; 2.51 \%]$} \\
\hline
\end{tabular}

Note: Asymptotic critical values are reported in Hansen (2000).

Table 7 shows the estimation of the degree of information rigidity for inflation values higher (or lower) than $\hat{\gamma}$, under the specification of Equation (5). This generates two parameters: $\lambda_{1}$ and $\lambda_{2}$ under high- and low- inflation regimes, respectively. The point estimates suggest that the degree of information rigidity parameter changes when inflation rates are either lower or higher than the $\hat{\gamma}$. Once more, this result is robust to different measures of inflation and the output gap.

Once more, we reject the null of flexible information. Our estimations suggest that under 
a low-inflation regime, $\widehat{\lambda}_{1}$ ranges from 0.39 to 0.42 (consistent with approximately 2.4 and 2.5 quarters of inattentiveness), while for high-inflation environments, $\widehat{\lambda}_{2}$ ranges from 0.65 to 0.69 (approximately 1.4 and 1.5 quarters). This result supports our hypothesis that economic agents update information faster in high-inflation environments, while in low-inflation environments, those agents lack incentives to update information.

It is important to mention that the relatively small standard deviation of $\widehat{\lambda}_{1}$ and $\widehat{\lambda}_{2}$ guaranty that $\widehat{\lambda}_{1}$ is statistically different than $\hat{\lambda}_{2}$. In other words, the upper band of the confidence interval for $\widehat{\lambda}_{1}$ does not cross paths with the lower band of the confidence interval for $\hat{\lambda}_{2}$ at 95 percent of the confidence level.

Table 7: Information rigidity in high and low inflation $\left(\alpha=0.1\right.$ and $j^{\max }+1=5$ quarters $)$

\begin{tabular}{ccccc}
\hline \hline & \multicolumn{2}{c}{$y^{\text {Quadratic Detrended }}$} & \multicolumn{2}{c}{$y^{\text {Hodrick-Prescott }}$} \\
\hline \hline \multirow{2}{*}{$\pi^{\text {CPI inflation }}$} & Low Inflation & High Inflation & Low Inflation & High Inflation \\
& $\left(\pi_{t-1} \leq 1.7 \%\right)$ & $\left(\pi_{t-1}>1.7 \%\right)$ & $\left(\pi_{t-1} \leq 1.7 \%\right)$ & $\left(\pi_{t-1}>1.7 \%\right)$ \\
& 0.37 & $\widehat{\lambda}_{1}$ & $\widehat{\lambda}_{1}$ & 0.39 \\
$\pi^{\text {Core inflation }}$ & $(0.047)$ & $(0.034)$ & $(0.061)$ & $(0.042)$ \\
& $\left(\pi_{t-1} \leq 2.5 \%\right)$ & $\left(\pi_{t-1}>2.5 \%\right)$ & $\left(\pi_{t-1} \leq 2.2 \%\right)$ & $\left(\pi_{t-1}>2.2 \%\right)$ \\
& 0.39 & $\widehat{\lambda}_{2}$ & $\widehat{\lambda}_{1}$ & 0.68 \\
$\pi^{\text {GDP deflator }}$ & $(0.061)$ & $(0.026)$ & $(0.042)$ & $(0.053)$ \\
& $\left(\pi_{t-1} \leq 2.3 \%\right)$ & $\left(\pi_{t-1}>2.3 \%\right)$ & $\left(\pi_{t-1} \leq 2.3 \%\right)$ & $\left(\pi_{t-1}>2.3 \%\right)$ \\
& 0.42 & $\widehat{\lambda}_{2}$ & $\widehat{\lambda}_{1}$ & 0.65 \\
Average & $(0.023)$ & $(0.042)$ & 0.48 & $(0.035)$ \\
In quarters & 0.39 & 0.69 & 0.42 & $0.652)$ \\
\hline
\end{tabular}

Note: The sample period is 1971Q1-2007Q4. Standard errors are in parentheses.

\section{Conclusions}

As emphasized by Lucas (1976), a model's ability to fit past data, especially when it relies on ad hoc assumptions about individuals' or firms' behavior, is not sufficient grounds for using it to analyze future changes in policy. The recent work on imperfect information, which includes sticky information, has focused on providing micro-foundations, leading to suggested reduced forms.

We provide direct estimations of the degree of information rigidity following the sticky information theory ( $\lambda$ parameter). Our results suggest different degrees of information rigidity across countries and across different time periods. We argue that the estimated levels of information 
rigidity appear to be driven primarily by state-contingent conditions of low- and high-inflation scenarios. In other words, in low-inflation environments, agents tend to be more inattentive to macroeconomic conditions.

We obtain consistent estimates of the slope of the SIPC for 12 OECD countries, following the strategy of Khan and Zhu (2006). Our results are in line with those of Döpke et al. (2008a), who consider a small sample of countries and a different way of incorporating inflation and output expectations, and with Coibion and Gorodnichenko (2012), who find information rigidity in a cross-country analysis based on the data of professional forecasters. We are able to reject the hypothesis of flexible information in favor of a degree of stickiness for all countries in the sample. Furthermore, we find evidence that suggests that periods of high inflation are associated with a faster information updating process, while periods of low inflation are associated with a slower information updating process. These results hold for different measures of inflation and the output gap.

The U.S. has differences in the duration of information stickiness between high- and lowinflation periods. Our previous estimates of the degree of information stickiness for OECD countries suggest that countries that have suffered relatively high average inflation or highly volatile inflation would tend to have a higher degree of information stickiness. We split the sample between periods with high and low inflation by estimating threshold models. We consider two scenarios: (i) estime a date that breaks the sample between high and low inflation, and (ii) estimate an inflation level that splits the sample between high and low inflation.

In all cases, we reject the hypothesis of flexible information. In all cases a higher degree of information stickiness is associated with high-inflation scenarios. These results are robust to different measurements of inflation and the output gap.

We are currently testing the exogeneity of $\lambda$ in line with the discussion in Lucas (1973), Ball, Mankiw and Romer (1988), and Kiley (2000) but in the context of the sticky information framework. ${ }^{12}$ Other topics that remain for future research are the use of different measures of marginal cost rather than the output gap and estimating the SIPC for developing countries.

\section{References}

Ball, L., G. Mankiw and D. Romer (1988). "The New Keynesian Economics and the OutputInflation Trade-off." Brookings Papers on Economic Activity 19(1), pp. 1-82.

Ball, L. and D. Romer (1990). "Real Rigidities and the Non-Neutrality of Money." Review of Economic Studies 57, pp. 183-203.

\footnotetext{
${ }^{12}$ Kiley (2000) points out that, in the literature, sticky prices help generate persistent output fluctuations in response to aggregate demand shocks; however, Kiley builds a model in which price stickiness is endogenous and generates persistent output fluctuations. Since the degree of price stickiness should be lower in high-inflation economies, Kiley argues that output persistence should also be lower in high-inflation economies. As evidence suggesting that output fluctuations about trend are less persistent in high-inflation economies, Kiley presents an estimation of the model, as well as simple autocorrelations of detrended real output.
} 
Carrera, C. (2012). "Estimating Information Rigidity Using Firms' Survey Data." B.E. Journal of Macroeconomics 12:1 (Topics), Article 13.

Carroll, C. (2003). "Macroeconomic Expectations of Households and Professional Forecasters". Quarterly Journal of Economics 118, pp. 269-298.

Chan, K.S. (1993): "Consistency and Limiting Distribution of the Least Squares Estimator of a Threshold Autoregressive Model." Annals of Statistics 21, pp. 520-533.

Chari, V.V., P.J. Kehoe and E.R. McGrattan (2000). "Sticky Price Models of the Business Cycle: Can the Contract Multiplier Solve the Persistence Problem?" Econometrica 68(5), pp. 1151-1179.

Coibion, O. (2010). "Testing the Sticky Information Phillips Curve." Review of Economics and Statistics 92(1), pp. 87-101.

Coibion, O. and Y. Gorodnichenko (2012). "What Can Survey Forecasts Tell Us About Informational Rigidities?" Journal of Political Economy 120, pp. 116-159.

Döpke J. J. Dovern, U. Fritsche and J. Slacalek (2008a). "Sticky Information Phillips Curves: European Evidence." Journal of Money, Credit, and Banking 40(7), pp. 1513-1520.

Döpke J. J. Dovern, U. Fritsche and J. Slacalek (2008b). "The Dynamics of European Inflation Expectations." B.E. Journal of Macroeconomics 8(1)(Topics), Article 12.

Gali, J. and M. Gertler (1999). "Inflation Dynamics: A Structural Econometric Analysis." Journal of Monetary Economics 44, pp. 195-222.

Hansen, B.E. (2000): "Sample Splitting and Threshold Estimation." Econometrica 68(3), pp. 575-603.

Khan, H and Z. Zhu (2006). "Estimates of the Sticky-Information Phillips Curve for the United States." Journal of Money, Credit, and Banking 38(1), pp. 195-207.

Kiley, M. (2007). "A Quantitative Comparison of Sticky-Price and Sticky-Information Models of Price Setting." Journal of Money, Credit, and Banking 39(1), pp. 101-125.

Kiley, M. (2000). "Endogenous Price Stickiness and Business Cycle Persistence." Journal of Money, Credit, and Banking 32(1), pp. 28-53.

Klenow, P. and J. Willis (2007). "Sticky information and sticky prices." Journal of Monetary Economics 54, pp. 79-99.

Korenok, O. (2008). "Empirical Comparison of Sticky Price and Sticky Information Models." Journal of Macroeconomics 30, pp. 906-927. 
Lucas, R.E. (1976). "Econometric Policy Evaluation: A Critique." Carnegie-Rochester Conference Series on Public Policy 1, pp. 19-46.

Lucas, R.E. (1973). "Some International Evidence on Output-Inflation Tradeoffs." American Economic Review 63(3), pp. 326-334

Mackowiak, B. and M. Wiederholt (2009). "Optimal Sticky Prices under Rational Inattention." American Economic Review 99(3), pp. 769-803.

Mankiw, N.G. and R. Reis (2002). "Sticky Information Versus Sticky Prices: a Proposal to Replace the New Keynesian Phillips Curve." Quarterly Journal of Economics 117(4), pp. 1295-1328.

Reis, R. (2006). "Inattentive Producers." Review of Economic Studies 73(3), pp. 793-821.

Rotemberg, J.J. and M. Woodford (1997). "An Optimization-Based Econometric Framework for the Evaluation of Monetary Policy." NBER Macroeconomics Annual 11, pp. 297-346.

Stock, J. and W. Watson (2001). "Forecasting Output and Inflation: The Role of Asset Prices." NBER Working Paper W8180.

Walsh, C. (2010). Monetary Theory and Policy. The MIT Press. 3rd Edition.

Woodford, M. (2003). Interest and Price. Princeton University Press.

\section{Appendix A. Data}

\section{Data Description}

We collect quarterly data for all countries in the sample and use an eight-year data period for iteratively forecasting inflation and the output gap in order to generate expectations of inflation and output. The estimation of the SIPC for each country is based on a $j^{\text {max }}$ equivalent to five years.

The main criterion for choosing the countries in the sample is the availability of data on GDP at constant prices. Data on inflation are relatively easy to find. However, data on GDP are more difficult given the change in the base year. Since GDP is the key variable for estimating the output gap, that limits the selection of countries in the sample. we build a database in line with Khan and Zhu (2006) and Stock and Watson (2001).

\section{Data Source}

The main source of the data is the International Financial Statistics (IFS) database. Other secondary sources are the OECD (for data on core inflation) and the Federal Reserve System (for data on capacity utilization for the U.S.). We also consider the global financial data database for long time series when they are not available in the IFS. 


\section{Data Employed}

For inflation forecasts, Khan and Zhu (2006) for the SIPC for the U.S. use the short-term interest rate (federal funds rate, level), dividend yield (S\&P 500 stock dividend yield, logarithm), term spread (difference between the 10-year government bond rate and the short-term interest rate, level), unemployment rate (level), capacity utilization (level), and the output gap (logarithm). For output gap forecasts, the variables are the short-term interest rate (level), dividend yield (logarithm), term spread (level), stock market price index (S\&P stock price index, growth), capacity utilization (level), and inflation (level).

We are able to use the same database for the U.S. and also to expand the range, in order to estimate a longer sample period for the SIPC.

As suggested by Stock and Watson (2001), we use the nominal effective exchange rate devaluation (level) and the terms of trade (level) to account for any pass-through from import prices to inflation and to capture possible effects from external shocks to the productive sector in the context of open economies.

In Table A1, we present the data used for forecasting inflation and the output gap for different countries.

Table A.1: Available information for forecasting

\begin{tabular}{lccccc}
\hline \hline & $\begin{array}{c}\text { Short } \\
\text { interest rate }\end{array}$ & $\begin{array}{c}\text { Spread } \\
\text { term }\end{array}$ & $\begin{array}{c}\text { Stock market } \\
\text { index }\end{array}$ & $\begin{array}{c}\text { Devaluation } \\
\text { exchange rate }\end{array}$ & $\begin{array}{c}\text { Terms of } \\
\text { trade }\end{array}$ \\
\hline Australia & $\mathrm{x}$ & $\mathrm{x}$ & $\mathrm{x}$ & $\mathrm{x}$ & $\mathrm{x}$ \\
Austria & $\mathrm{x}$ & $\mathrm{x}$ & $\mathrm{x}$ & $\mathrm{x}$ & $\mathrm{x}$ \\
Canada & $\mathrm{x}$ & $\mathrm{x}$ & $\mathrm{x}$ & $\mathrm{x}$ & $\mathrm{x}$ \\
Finland & $\mathrm{x}$ & & $\mathrm{x}$ & $\mathrm{x}$ & $\mathrm{x}$ \\
France & $\mathrm{x}$ & $\mathrm{x}$ & $\mathrm{x}$ & $\mathrm{x}$ & $\mathrm{x}$ \\
Germany & $\mathrm{x}$ & $\mathrm{x}$ & $\mathrm{x}$ & $\mathrm{x}$ & $\mathrm{x}$ \\
Korea & $\mathrm{x}$ & $\mathrm{x}$ & $\mathrm{x}$ & $\mathrm{x}$ & $\mathrm{x}$ \\
Norway & $\mathrm{x}$ & $\mathrm{x}$ & $\mathrm{x}$ & $\mathrm{x}$ & $\mathrm{x}$ \\
Spain & $\mathrm{x}$ & $\mathrm{x}$ & $\mathrm{x}$ & $\mathrm{x}$ & $\mathrm{x}$ \\
Switzerland & $\mathrm{x}$ & $\mathrm{x}$ & $\mathrm{x}$ & $\mathrm{x}$ & $\mathrm{x}$ \\
U.K. & $\mathrm{x}$ & $\mathrm{x}$ & $\mathrm{x}$ & $\mathrm{x}$ & $\mathrm{x}$ \\
U.S.1/ & $\mathrm{x}$ & $\mathrm{x}$ & $\mathrm{x}$ & & \\
\hline 1/ Information & on & $\mathrm{m}$ & & &
\end{tabular}

